\title{
O riso como expressão de um posicionamento na cidade: o encontro de Demócrito e Hipócrates
}

Priscilla Gontijo Leite

FAFICH-UFMG

priscillagontijo@yahoo.com.br

\begin{abstract}
The Pseudo-Hippocratic letters relate the fictitious meeting between Democritus and Hippocrates. This document is the basis which allows us to think about how the hippocratic tradition and Democritus' philosophy treat the concepts of man's and city's health. This paper aims to show some aspects of the relationship between man and the city, given the concept of health present in the Pseudo-Hippocratic Letters and also in both traditions which inspire them. KEYWORDS: Hippocrates; Democritus; philosophy; medicine.
\end{abstract}

Hoje é comum, nos meios de comunicação e, mesmo, nas conversas mais informais, ouvirmos acerca da proliferação de doenças provocadas pelos "males" existentes nos grandes centros urbanos: poluição, longos e demorados congestionamentos no trânsito, exposição excessiva a ruídos, alimentação rica em gordura e açúcar, sedentarismo, entre vários outros que poderíamos incluir numa lista extensa. De acordo com profissionais da saúde, as condições externas podem provocar alterações fisiológicas nos indivíduos, agravando ou, até mesmo, provocando doenças. Entre as doenças das grandes cidades, que afetam diretamente o estado emocional e mental do ser humano, podemos citar o "stress", a insônia, a irritação constante, as fobias e a depressão. Dessas, o "stress" ocupa um lugar de destaque na mídia, sendo corriqueira sua presença nos noticiários. Ele também é muito presente na linguagem cotidiana, sendo utilizado para expressar um estado de desgaste e esgotamento das forças, tanto físicas quanto emocionais. Todos já disseram ou ouviram de pessoas próximas a expressão estou "estressado". Isso se tornou um lugar-comum tão banal em nossa fala que muitas vezes a empregamos, sem, contudo, perceber que o seu conteúdo demonstra uma forma de nos relacionarmos com a cidade.

Outra expressão usualmente utilizada em nossa fala, diante de diversos problemas, é "ter de rir para não chorar". Ela é instigante, pois demonstra atitude contrária à normalmente esperada. Ao refletir acerca dessa expressão, podemos pensar no riso ${ }^{1}$ como a manifestação de um posicionamento do indivíduo diante da cidade.

\footnotetext{
${ }^{1}$ Para maiores informações sobre a questão do riso, principalmente da sua relação com o filósofo, cf. conferência de Quentin Skinner. La philosophie et le rire. Conférences Marc Bloch. http://cmb.ehess.fr/document54.html (acesso em 22 de maio de 2007).
} 
Nossa reflexão acerca do riso e da cidade foi conduzida a partir da leitura das Cartas pseudo-hipocráticas, reunidas sob o título Sobre o riso e a loucura. Elas narram o encontro fictício entre o médico Hipócrates e o filósofo Demócrito, que é caracterizado como doente por seus concidadãos. Esses, preocupados com a saúde de seu mais ilustre companheiro, pedem ao médico para curá-lo. Na leitura das Cartas, percebe-se que o autor possui um amplo conhecimento da tradição hipocrática e da filosofia de Demócrito. A datação e a autoria dessa obra são incertas. Quem as escreve assina como Hipócrates, assumindo a identidade dessa personagem para fazer sua crítica acerca da medicina. Sobre a datação, sabe-se que pertencem à Antiguidade tardia, estabelecendo-se como datas-limite o período entre fins do séc. I a.C. e o séc. I d.C. ${ }^{2}$

Pensando na perspectiva da relação entre o indivíduo e a cidade, a tradição hipocrática propõe que o estilo de vida, a dieta ${ }^{3}$ dos habitantes, pode ser a causa de doenças. No tratado hipocrático Da natureza do homem, tem-se como causa principal a dieta quando diferentes doenças surgem ao mesmo tempo:

Mas quando doenças de toda espécie surgem ao mesmo tempo, é evidente que as dietas são a causa, cada qual de uma doença respectiva, e o procedimento de cura deve ser realizado contra o verdadeiro motivo da doença, como foi dito por mim também algures, e pela mudança das dietas. ${ }^{4}$

Segundo Hipócrates, a saúde de uma pessoa é estritamente relacionada com a dieta que ela mantém, e sua doença significa que algum elemento dessa está em desarmonia. Assim, para restabelecer a saúde, o médico deve adequar os elementos que se encontram discrepantes na dieta. Por esse motivo, é importante para o médico ter conhecimento dos hábitos dos habitantes e das condições climáticas da cidade.

A relação dos homens com a cidade constitui importante objeto de reflexão da filosofia. A afinidade da filosofia por esse tema está na base de seu surgimento, já que ela se relaciona com o advento da pólis. A filosofia desenvolve-se no âmbito da problematização do poder exercido no campo político, sendo o resultado de uma reflexão sobre os problemas que se vivem na cidade. Assim, a filosofia, nas palavras do

\footnotetext{
${ }^{2}$ Cf. Pigeaud, J. La maladie de l'âme. Étude sur la relation de l'âme et du corps dans la tradition medico-philosophique. Paris: Les Belles Lettres, 2006, p. 452.

${ }^{3}$ Por dieta, entende-se um estilo de vida que envolve todas as atividades humanas, não se restringindo apenas à esfera da alimentação.

${ }^{4}$ Cf. Hipócrates, Da natureza do homem, 9 (tradução de Henrique F. Cairus).
} 
helenista Vernant, é "filha da cidade". 5

A relação cidade e indivíduo, a partir da relação saúde e doença, surge em diversos registros na Grécia Antiga. Além de nos tratados hipocráticos e em obras filosóficas, ainda encontramos tal relação na literatura. Um exemplo é a tragédia Édipo $R e i$, que se inicia com a demonstração do tema. No prólogo da tragédia de Sófocles, a peste se abate sobre a cidade de Tebas, pois há nela alguém que incorreu num crime e não foi devidamente punido. Para além de toda a esfera religiosa que permeia o prólogo ${ }^{6}$ e foge do escopo de reflexão deste trabalho, podemos ressaltar que ele evidencia poder a ação indevida de um dos membros da cidade torná-la doente; sua cura, por outro lado, dar-se-á por meio da eliminação, ou purgação, do mal que a afeta. ${ }^{7}$ Em Édipo Rei, o sofrimento de Édipo se confunde com o da cidade. Ela é uma unidade, e sofre como o corpo devido a um excesso, ou uma falta, pois sua symmetría foi quebrada. Semelhantemente, na tradição hipocrática, tem-se que o mal que afeta o corpo deve ser purgado com o remédio apropriado para restabelecer-lhe a ordem, como demonstra o tratado Da natureza do homem: "Se deres ao homem um remédio que remova fleuma, ele vomita fleuma, se lhe deres um remédio que remova bile, ele remove a bile", 8

Para entender como a cidade e o homem se relacionam por meio dos termos saúde e doença nas Cartas, primeiramente mostraremos como o indivíduo e a pólis são pensados nas duas tradições que as inspiram. No pensamento grego, de modo geral, a pólis era entendida como um conjunto organizado, um kósmos que se torna harmonioso quando cada um de seus componentes está no devido lugar. Tal harmonia é quebrada quando um dos seus elementos está fora da ordem, o que pode provocar um distúrbio sobre toda a cidade. ${ }^{9}$

$\mathrm{Na}$ tradição hipocrática, as cidades possuem natureza singular. Elas se diferenciam devido à variação dos elementos que as compõem, sejam eles relativos a

\footnotetext{
${ }^{5}$ Cf. Vernant, J.-P. As origens do pensamento grego. Tradução de Ísis Borges da Fonseca. São Paulo: Difel, 1986, p. 95.

${ }^{6}$ Francisco Marshal defende que o prólogo possui um contexto religioso de ação. Há uma crise na esfera do sagrado que irá impelir Édipo à investigação para descobrir o responsável pelos distúrbios em Tebas, levando-o ao impasse trágico de descobrir sua verdadeira identidade. Cf. Marshal, F. Súplica e responsabilidade. In: Édipo tirano. A tragédia do saber. Porto Alegre/ Brasília: UFRS/ UNB, 2000 .

${ }^{7}$ Para maiores informações sobre as relações entre míasma e katharós presentes na obra de Sófocles, na tradição hipocrática e no pensamento grego em geral cf. Moulinier, L. Le pur et l'impur dans la pensée des grecs. D'Homere a Aristote. Paris: Klincksieck, 1952.

${ }^{8}$ Cf. Hipócrates, Da natureza do homem, 5 (tradução de Henrique F. Cairus).

${ }^{9}$ Cf. Vernant, op. cit., 1986, p. 96.
} 
aspectos geográficos, como a constituição dos solos, das águas e o seu posicionamento no relevo, ou a características de seu povo, como o biótipo, seus hábitos alimentares e todos os outros aspectos culturais. Por serem as cidades diferentes, um médico nunca possui um conhecimento total, mas apenas relativo àquilo que suas próprias experiências lhe permitiram determinar. Desse modo, toda vez que um médico visita uma nova cidade, não possui os conhecimentos necessários para diagnosticar as doenças que ocorrem nela, pois isso somente é possível depois de observadas as condições climáticas e os hábitos culturais. Em seu tratado dos Ares, águas e lugares, Hipócrates sugere que quem quiser dedicar-se à arte médica deve primeiramente atentar para as condições geográficas de uma certa cidade:

Quem quiser investigar corretamente a medicina deve fazer o seguinte: primeiramente deve levar em consideração as estações do ano e o que cada uma delas pode produzir. [...] Assim que alguém chega a uma cidade, é inexperiente sobre ela. É preciso estar atento à posição dela, a como está assentada, e aos ventos e aos nascentes do sol; pois não podem ter a mesma propriedade a (cidade) que está voltada para o bóreas e a que se volta para o noto, nem a que se volta para o sol que se ergue e a que se volta para o sol se pondo. ${ }^{10}$

Esse tratado evidencia que o médico atua no limite do nómos sobre a phýsis, por meio da demonstração de como as phýseis das diversas regiões podem afetar a phýsis do homem e de como as singularidades, os nómoi, podem afetar a saúde humana. Entre a phýsis e o nómos encontra-se o homem, que participa ativamente dessa tensão, pois está inserido numa phýsis, mas tenta sempre trazê-la para o domínio do nómos. Pelo fato de a medicina operar entre phýsis e nómos, ela opera com o contingente e a indeterminação, constituindo-se numa tékhne.

Prosseguindo com seu argumento em Ares, águas e lugares, Hipócrates afirma que, depois de realizadas tais observações, o médico deve "considerar cada caso", ${ }^{11}$ pois, da mesma forma que as cidades tem uma natureza singular, os homens também possuem constituições diferentes umas das outras.

O homem, no Corpus Hippocraticum, possui uma natureza única. Isso constitui mais um motivo para a medicina não ser fundamentada em hipóteses, mas na experiência, nas observações e no cálculo. A partir dessa concepção, rejeitam-se as hipóteses e valorizam-se a técnica e a experiência, como demonstra o tratado Medicina

\footnotetext{
${ }^{10}$ Cf. Hipócrates, Ares, águas e lugares I 1 (tradução de Henrique F. Cairus).
}

${ }^{11}$ Cf. Hipócrates, Ares, águas e lugares I 1 (tradução de Henrique F. Cairus). 
antiga. ${ }^{12}$ Com isso, a medicina promove seu desligamento da filosofia, delimitando um campo de atuação próprio, e, ainda, reivindica uma visão de mundo que concorre com a dela.

A constituição singular do homem faz com que o conceito de saúde seja relativo, já que cada homem possui um estado de saúde que lhe é próprio e não se repete em outro indivíduo:

O corpo do homem contém sangue, fleuma, bile amarela e negra; esta é a natureza do corpo, através da qual adoece e tem saúde. Tem saúde, precisamente quando estes humores são harmônicos em proporção, em propriedade e em quantidade, e sobretudo quando são misturados. O homem adoece quando há falta ou excesso de um desses humores, ou quando ele se separa no corpo e não se une aos demais. ${ }^{13}$

Segundo Claude Mossé, por trás da noção de equilíbrio do corpo, e, então, de saúde, transparece a adoção de um modelo político, o da democracia. Para tal afirmação, ela se baseia em Álcmeon de Crotona, que afirma ser "o princípio da saúde a igualdade (isonomía) ${ }^{14}$ das qualidades - úmida, seca, fria, quente, amarga e doce -, enquanto, a dominação (monarchía), a causa das enfermidades". 15

Na tradição hipocrática, entre o mundo externo (fatores climáticos e geográficos) e o mundo interno (corpo e alma), há uma relação análoga de macrocosmo e microcosmo. Essa continuidade, para Catherine Darbo-Peschanski, ${ }^{16}$ ocorre de três maneiras: a primeira é material, e um exemplo é o fato de o homem ser constituído dos mesmos elementos do mundo exterior; por isso, pode nutrir-se do que a natureza lhe oferece. A segunda é funcional: por exemplo, a água e o fogo estão presentes tanto no homem quanto no mundo externo, e tudo é resultante da mistura desses dois elementos.

\footnotetext{
${ }^{12}$ Cf. Hipócrates, Medicina antiga, 1-2 (tradução de W. H. S. Jones).

${ }^{13}$ Cf. Hipócrates, Da natureza do homem, 4 (tradução de Henrique F. Cairus).

${ }^{14}$ Isonomia é um dos conceitos fundamentais para o desenvolvimento da democracia. Ela representa a igual participação de todos os cidadãos no exercício do poder. A palavra foi utilizada por Heródoto demonstrando a igualdade legal alcançada pelas reformas de Clístenes e a igualdade ocasionada pelas reformas de Sólon (cf. Vernant, op. cit., 1986, p. 42).

${ }^{15}$ Cf. Mossé, C. Dicionário da civilização grega. Tradução de Carlos Ramalhete e André Telles. Rio de Janeiro: Zahar, 2004, p. 99.

${ }^{16}$ Cf. Darbo-Peschanski, C. Ordre du corps, ordre du monde: aitia, tekmêrion, sêmeion, historion dans quelques traités hippocratiques de la fin du Ve. siècle avant notre ère. In: I Simpósio Internacional de Estudos Antigos-IV Seminário Internacional Archai: Saúde do homem e da cidade na Antiguidade Greco-Romana, 2007, Parque Natural do Caraça. Anais do I Simpósio Internacional de Estudos AntigosIV Seminário Internacional Archai: Saúde do homem e da cidade na Antiguidade Greco-Romana. Belo Horizonte: FAFICH/ UFMG, 2007. Vol. I (cd-rom, p. 1-4).
} 
Por fim, tem-se a continuidade estrutural, cujo exemplo é que o corpo e a alma são dotados de uma estrutura territorial fixa, ocupada por elementos diferentes como no mundo exterior.

A relação entre o microcosmo e o macrocosmo também é encontrada na filosofia de Demócrito, que a utiliza para demonstrar como o homem pode conseguir, para ele e para cidade, uma existência equilibrada e, com isso, alcançar a felicidade. $\mathrm{O}$ equilíbrio, symmetría, é representado pelo justo meio entre duas medidas extremas, pois tanto o excesso quanto a falta são condenáveis. A busca por essa symmetría constitui a razão de ser da existência humana.

Para conseguir a justa medida, o homem deve estar em contínuo exercício de reflexão, e este se dá através do movimento de átomos em seu corpo. É por meio dessa justa medida que o homem alcança o equilíbrio em todos os domínios de sua vida, inclusive em sua relação com o outro, ou seja, em sua vida social e política. Portanto, nota-se que a ética de Demócrito se liga à sua física, a teoria atômica.

A questão central na reflexão ética de Demócrito é a eudaimonía, ou felicidade, que é o resultado da justeza obtida pelo homem. É através dessa justeza que o homem consegue equilibrar sua alma, sendo esse equilíbrio dinâmico e reconhecido pelo constante exercício da reflexão. Com isso, consequentemente, ele também atinge a euthymía, o bom ânimo. A eudaimonía é definida por sua relação com a alma e é explicada a partir dos termos "bom ânimo", "bem-estar" e "harmonia". Outro termo relacionado à reflexão ética do filósofo é ataraxía, que corresponde a um estado de ausência de perturbações. Ela consiste em não ultrapassar o limite próprio a cada natureza. Para o filósofo, o homem não deve "procurar mais que suas forças permitem, pois uma plenitude razoável é coisa mais segura que uma superplenitude". ${ }^{17}$

Dessa forma, estar de "bom ânimo" implica em ter uma vida equilibrada, sem excessos que possam arruinar a tranquilidade da alma. Para ter essa moderação, o homem deve recorrer à razão para discernir aquilo que ultrapassa sua própria natureza. A razão é utilizada circunstancialmente e proporciona a justa medida, a qual é justa por adaptar-se a um dado momento. Por meio dela, o homem conseguirá o bem-viver na cidade.

Assim, para Demócrito e Hipócrates, o homem é constituído por elementos que

${ }^{17}$ Cf. Demócrito, DK 68 B 3. Os fragmentos de Demócrito utilizados neste trabalho são todos retirados da tradução de Paulo F. Flor, presentes na coleção Os Pensadores. 
se arranjam de maneira a constituir uma natureza peculiar a cada um. Para o primeiro, esses elementos são os átomos, para o segundo, o sangue, a fleuma, a bile amarela e negra. Dessa forma, para ambos, cada ser humano é específico e tenta estabelecer com a cidade uma relação que proporcione o bem-viver, o qual, na tradição hipocrática, corresponderá à saúde e, na filosofia de Demócrito, à eudaimonía.

Na filosofia de Demócrito, existe a preocupação com o bom funcionamento da cidade. Num estado ideal, a cidade supera todos seus conflitos, pois, somente no estado de paz, ela se pode desenvolver: "Pela concórdia torna-se possível realizar grandes obras e, para as cidades, as seguras; de outra maneira, não". ${ }^{18}$ Nota-se uma crítica ao estado de guerra, de que se recorda o autor das Cartas no momento em que a personagem de Demócrito se lamenta por estarem os homens em constantes embates: "Os homens jamais vivem em paz". 19

Uma cidade harmoniosa é aquela em que seus cidadãos respeitam as leis, agindo com justiça. Para Demócrito, justiça "é fazer o que é preciso; injustiça, não fazer o que é preciso, mas deixá-lo de lado". ${ }^{20}$ Para ele, todos os que cometem injustiças devem ser punidos. $^{21}$ A falta de respeito às leis provoca uma série de distúrbios, uma vez que elas foram responsáveis por "impedir que cada um vivesse de acordo com o seu próprio gosto [...]". ${ }^{22}$ A lei garante o bom convívio entre os homens, ${ }^{23}$ mas, para que isso aconteça, eles devem obedecê-las, não prejudicando, através da desmedida, a si mesmos ou aos outros.

Para a manutenção do bom funcionamento das leis, Demócrito defende a pena de morte nos fragmentos DK 68 B $257^{24}$ e DK 68 B 258. ${ }^{25}$ Além da pena de morte, a justiça grega tinha outros mecanismos que excluíam socialmente todos aqueles que eram considerados nocivos, tais como o ostracismo, a graphē paranómōn e os processos

${ }^{18}$ Cf. Demócrito, DK 68 B 251 (tradução de Paulo F. Flor).

${ }^{19}$ Cf. Pseudo-Hipócrates, Sobre o riso e a loucura (Carta de Hipócrates a Damagete, em minha tradução do francês ).

${ }^{20}$ Cf. Demócrito, DK 68 B 256 (tradução de Paulo F. Flor).

${ }^{21}$ Cf. Demócrito, DK 68 B 256: “Aos que sofrem injustiças é preciso, dentro do possível, vingar e nisso não ser omisso. Agir assim é justo e bom, mas não fazê-lo é injusto e mau” (tradução de Paulo F. Flor).

${ }^{22}$ Cf. Demócrito, DK 68 B 245 (tradução de Paulo F. Flor).

23 Cf. Demócrito, DK 68 B 248: “A lei quer beneficiar a vida dos homens, mas pode fazê-lo quando eles querem receber o benefício, pois indica para os que o querem a virtude que lhe é própria" (tradução de Paulo F. Flor).

${ }^{24}$ Cf. Demócrito DK 68 B 257: "Em alguns seres vivos, eis como fica a questão: 'Quem matarás ou não matarás?' - Quem mata o que comete injustiça ou quer cometê-la fica impune e, para o bem estar, antes fazê-lo do que não fazê-lo" (tradução de Paulo F. Flor).

${ }^{25}$ Cf. Demócrito DK 68 B 258: "É preciso a todo custo matar os seres vivos que, transgredindo a justiça, fazem mal a outrem. Quem o fizer terá maior quinhão de ânimo, de justiça e de posses em toda sociedade organizada" (tradução de Paulo F. Flor). 
de impiedade. ${ }^{26} \mathrm{O}$ primeiro era o afastamento físico da cidade por certo período de tempo; a segunda era o procedimento jurídico no qual alguém era processado por fazer uma proposta ilegal na Assembleia; os terceiros aconteciam quando alguém era processado por ter cometido atos ímpios.

A boa ordem da cidade seria fundamental para que o homem alcançasse a felicidade, pois ele apenas o conseguiria quando estivesse inserido nela. Mas, para isso, era necessário que ela fosse "bem dirigida", 27 de forma que os homens a governassem bem e respeitassem as leis, buscando sempre "nada fazer de inadequado". ${ }^{28}$

Após essa exposição de alguns elementos presentes nas tradições que compõem as Cartas, passaremos à sua análise. Nelas, o autor promove uma discussão entre os saberes médico e filosófico representados pelas figuras-chave: Hipócrates e Demócrito. As Cartas se iniciam com o apelo dos cidadãos de Abdera a Hipócrates para que salve a cidade que, segundo eles, corre grande perigo: um dos seus cidadãos mais ilustres, Demócrito, estaria louco. Segundo os concidadãos do filósofo, ele enlouquecera porque ria tanto das coisas boas quanto ruins, e isso lhes causava muito incômodo.

Sob a perspectiva do médico, não haveria problema algum com o riso em si ou com o número de vezes em que ele ocorria, mas sim com o seu caráter inoportuno. $\mathrm{O}$ riso, indesejável para os cidadãos, não está de acordo com o nómos. Ele demonstra um desajuste, um comportamento inadequado diante da cidade, que é nocivo, uma vez que o filósofo não estaria cumprindo sua função social. Na Grécia Antiga, a identidade de uma pessoa se baseava no reconhecimento de seu valor como cidadão dado pelos pares. Cada pessoa estava sujeita ao olhar alheio, e sua existência se relacionava com esse olhar: vivia-se sob os olhos dos outros. ${ }^{29}$ Como a consideração social do cidadão era idêntica à sua identidade, ele devia participar ativamente da pólis em todos os domínios (político, jurídico, social e religioso). Dessa forma, a responsabilidade de fazer com que

\footnotetext{
${ }^{26}$ Para mais informações sobre essas medidas de regulamentação e manutenção da pólis, cf. Finley, M. I. Política no mundo antigo. Tradução de Álvaro Cabral. Rio de Janeiro: Zahar, 1985 e Finley, M. I. Democracia: antiga e moderna. Tradução de Waldéa Barcellos e Sandra Bedran. Rio de Janeiro: Graal, 1988.

${ }^{27}$ Cf. Demócrito, DK 68 B 252: "É preciso julgar de maior importância que tudo o que interessa à cidade, para que sejam bem dirigidas sem armas contendas contrárias ao direito e sem assumir para si um poder contrário ao bem comum. Uma cidade bem dirigida é maior apoio e tudo nela está contido: salva a cidade, tudo está salvo; destruída a cidade, tudo está destruído" (tradução de Paulo F. Flor).

${ }^{28}$ Cf. Demócrito, DK 68 B 264: "Em nada respeitar mais os homens que a si mesmo, nem fazer algo mau, quer ninguém vá ver, quer todos os homens. Ao contrário, respeitar principalmente a si mesmo e estabelecer para sua alma esta lei: nada fazer de inadequado" (tradução de Paulo F. Flor).

${ }^{29}$ Para maiores informações sobre a questão do outro para a constituição da indetidade na Grécia Antiga cf. Vernant, J.-P. Sob os olhos do outro. In: Murachco. São Paulo: EDUSP, 2001, p. 343-344. Entre mito e política. Tradução de Cristina
} 
a pólis estivesse harmônica era de todos os cidadãos. Por isso, os cidadãos de Abdera, preocupados com restabelecer o equilíbrio de sua cidade, convidam Hipócrates para curar Demócrito de sua loucura: ele estaria, assim, recuperando o equilíbrio do nómos da cidade $^{30}$ ao devolver a saúde ao filósofo. Isso está de acordo com a tradição hipocrática, segundo a qual a saúde da cidade depende da saúde do homem. As Cartas questionam essa premissa e demonstram as limitações da medicina hipocrática na cura das pessoas, pois ela não seria capaz de solucionar os problemas relacionados à alma.

O caso de Demócrito logo intriga Hipócrates. O primeiro fato que chama a atenção do médico é a excessiva preocupação da cidade com a saúde de um único indivíduo: "Surpreende-me que a cidade esteja em tumulto como um único ser humano, por causa de um ser humano". ${ }^{31}$ Nessa passagem, percebe-se que a cidade é comparada a um corpo vivo, que se agita por causa de um desequilíbrio entre seus elementos. Tal analogia continua ao longo das Cartas, como, por exemplo, na de Hipócrates a Dionísio de Halicarnaso, em que o médico afirma estar a cidade doente devido à doença de um de seus cidadãos, formando os cidadãos-cidade uma única alma. Na carta direcionada a Demagetes, por sua vez, Hipócrates diz que deve ir a Abdera para curar a cidade da doença de um único Demócrito. Tais exemplos demonstram que a cidade é apresentada como um corpo, que pode sofrer contaminação e cair doente, se um dos elementos estiver contaminado.

Chegando Hipócrates a Abdera, os cidadãos pedem ao médico que dê seu diagnóstico, mas ele reluta em fazê-lo: somente o pode depois de examinar, com seus próprios sentidos, o verdadeiro estado do filósofo. Esse comportamento, como vimos, está de acordo com a medicina hipocrática, que é favorável às atitudes empíricas.

Antes de visitar Demócrito e comprovar o estado de sua saúde, Hipócrates levanta a suspeita de que ele não esteja louco, como acreditavam seus concidadãos, mas, sim, sofrendo de melancolia. ${ }^{32}$ Ele chega a essa conclusão após analisar alguns indícios apresentados pelos cidadãos de Abdera em seu apelo: insônia (Demócrito não dorme nem de dia nem de noite), esquecimento (ele se esquece de tudo, inclusive de si mesmo)

\footnotetext{
${ }^{30}$ Segundo Cairus, Demócrito é representante de um éthos, e, por isso, instaurador de um nómos. A mudança de éthos de Demócrito comprometeria todo o nómos (cf. Cairus, H. F. A fala razoável da loucura: o riso de Demócrito. Calíope. Rio de Janeiro, vol. XI, 2003, p. 76).

${ }^{31}$ Cf. Pseudo-Hipócrates, Sobre o riso e a loucura (Carta de Hipócrates ao senado do povo de Abdera, em minha tradução do francês).

${ }^{32}$ A melancolia que acomete os homens públicos, principalmente os excelentes, é analisada no Problema $\mathrm{XXX}, 1$ de Pseudo-Aristóteles. Segundo o autor, os homens excelentes estão mais propensos a serem melancólicos, o que pode gerar um problema para a cidade, pois o bom governo depende deles.
} 
e o riso (suposto sinal de sua "loucura").

$\mathrm{Na}$ Carta dirigida a Filopêmene, Hipócrates descreve o comportamento do melancólico:

[Eles são] às vezes taciturnos e solitários, evadem-se para lugares isolados; desviam-se dos homens, olham o seu semelhante como um estrangeiro; mas também não é raro, nos que se consagram ao saber, que a sua disposição à sabedoria os incite a esquecer qualquer outra preocupação. ${ }^{33}$

Assim, uma das características da melancolia é o isolamento do indivíduo na cidade. O isolamento diante do corpo social representa um perigo, pois pode comprometer os laços de sociabilidade que o integram. Da mesma forma, o isolamento é um dos motivos para o surgimento de doenças, de acordo com o tratado Da natureza do homem: "O homem adoece quando há falta ou excesso de um desses humores, ou quando ele se separa no corpo e não se une aos demais". ${ }^{34}$ A cidade, assim como o corpo, é um todo equilibrado em harmonia dinâmica, que adoece quando qualquer de suas partes está fora do lugar.

Nas Cartas, Demócrito e Abdera formam o duplo parte/ todo em discordância, havendo, por isso, a doença. Tal discordância advém do isolamento de uma parte, isto é, de Demócrito, que não está interagindo com a cidade. Ele não está cumprindo sua função social, que é a dar conselhos aos cidadãos. Essa é a dyácrasie que Hipócrates é chamado a curar. ${ }^{35}$

Para o autor das Cartas, a personagem Demócrito está melancólico e não louco. O filósofo se recolhe para deixar sua alma em paz. A procura da suspensão de perturbações está de acordo com a ataraxía democritiana. O filósofo precisa de um momento consigo mesmo para refletir acerca de si, dos homens e da relação que eles mantém com a cidade. $\mathrm{O}$ isolamento demonstra sua atitude perante a cidade: a condenação das ações dos homens. Por isso, a ataraxía não significa uma negação da cidade e de sua atividade política. Semelhantemente, o melancólico também apresenta

\footnotetext{
${ }^{33}$ Cf. Pseudo-Hipócrates, Sobre o riso e a loucura (Carta de Hipócrates a Filopêmene, em minha tradução do francês).

${ }^{34}$ Cf. Hipócrates, Da natureza do homem, 4 (tradução de Henrique F. Cairus).

${ }^{35} \mathrm{Cf}$. Ayache, L. Le cas de Démocrite: du diagnotic médical à l'évalutation philosophique. In: Wittem, R.; Pellegni, P. (org.). Hippokratische Medizin und antike Philosophie. Verhandlungen des VIII Internationalen Hippokrates-kolloquiums in Kloster Banz Staffelstein. Olms: Weidmann, 1993. Vol. XXIII, p. 66.
} 
esse comportamento.

Na carta dirigida a Damagetes, tem-se a narrativa do encontro entre Demócrito e Hipócrates. O médico é conduzido pelos cidadãos até o lugar onde Demócrito se encontra, e esses observam sua situação com profunda tristeza. A descrição física de Demócrito (sujo, com uma túnica grosseira e barba longa) corresponde a um dos sinais elencados pelos cidadãos: ele se esquece de tudo, até de cuidar de si próprio. Esse descuido com o próprio corpo revela-lhe o comportamento diante do corpo social, pois ele também se omite quanto à cidade naquilo que seus concidadãos esperam dele.

Hipócrates pergunta a Demócrito pelo motivo do seu riso. Ele responde que ri da irracionalidade dos homens, da sua ganância, de suas guerras e de suas preocupações com o efêmero. Sobre a ganância, a personagem de Demócrito afirma, nas Cartas, que leva à desmesura de querer sempre mais e nunca satisfazer-se: "Quando não são ricos, desejam a riqueza; adquirindo-a, eles a escondem e subtraem-na aos olhares". ${ }^{36}$ Nos fragmentos de Demócrito, encontramos dois que também condenam a atitude gananciosa, caracterizando-a como capaz de provocar sofrimentos. O primeiro fragmento aconselha aos homens não sofrerem em demasia por aquilo que não possuem: "Sensato é quem não sofre pelo que não tem, mas se alegra pelo que tem". ${ }^{37}$ O segundo condena aquele que age com desmedida, e preocupa-se excessivamente com seus bens: "Afortunado quem deseja com medida, infortunado quem sofre pelo que muito tem". 38

Assim, o riso de Demócrito não está relacionado ao que acontece de bom ou de ruim ao homem, mas é direcionado à sua irracionalidade. $\mathrm{O}$ motivo do riso de Demócrito é a euthymía, o bom ânimo. ${ }^{39}$ A razão transforma o thymós em euthymía. Somente quando o ânimo está sob a direção do intelecto pode ser proveitoso para o homem. O saber bem calcular para evitar os extremos é importante para a manutenção do bom ânimo, pois

para os homens, o bom ânimo vem a existir com a moderação de alegria e comedimento de vida. As coisas que faltam e as que sobram costumam sofrer mudanças e produzir na alma grandes comoções

\footnotetext{
${ }^{36}$ Cf. Pseudo-Hipocrátes, Sobre o riso e a loucura (Carta de Hipócrates a Damagete, em minha tradução do francês).

${ }^{37}$ Cf. Demócrito, DK 68 B 231 (tradução de Paulo F. Flor).

${ }^{38}$ Cf. Demócrito, DK 68 B 286 (tradução de Paulo F. Flor).

${ }^{39}$ Cf. Peixoto, M. C. D. A felicidade como simetria da alma em Demócrito. Boletim do C.P.A. Campinas, vol. 20/ 21, p. 125, 2007.
} 
(...). [O homem deve,] portanto, voltar o pensamento ao que é possível e satisfazer-se com o que está à mão. ${ }^{40}$

Nas Cartas, sobre a suposta melancolia de Demócrito, o autor defende que não vem da bile negra, contrariando a tradição hipocrática. Ela não é uma doença do corpo, mas sim um estado d'alma. O riso é uma terapia e tem um poder curativo, podendo purgá-la; ele não é a expressão da loucura do filósofo, mas de sua grande sabedoria diante dos homens. Então, se num primeiro momento a cidade parece sábia por se preocupar com a saúde de um de seus cidadãos, no final é mostrada como ignorante por não entender o riso de Demócrito...

Portanto, o que oferece melhor remédio para o melancólico: a filosofia ou a medicina? No final das Cartas, fica clara a opção do autor pela filosofia, considerando-a superior à arte médica, pois Hipócrates reconhece a sabedoria de Demócrito e considera que a cidade é que está verdadeiramente doente. O método de Hipócrates não se apresenta como apto para curar as doenças d'alma, e seu relativismo é questionado.

Assim, o riso de Demócrito, num primeiro momento encarado como sinal de doença, mostra-se o remédio mais eficaz contra os problemas enfrentados na cidade. Esses problemas são o resultado de conflitos nas relações humanas, gerados pelo mau uso da razão. Na tradição hipocrática, a doença, definida como desequilíbrio, traz, em sua relação analógica entre a coletividade e o indivíduo, a evidência de que o elemento perturbador da sociedade deve ser eliminado, como deve ser purgado um humor patológico. A desarmonia entre nómos e phýsis é responsável pelas mazelas coletivas. O médico deve dedicar-se para que as duas esferas fiquem harmônicas, deve corrigir o nómos em função da phýsis, e, através do nómos, testar-lhe os limites. Esse é o princípio do phármakon, que restabelecerá a harmonia na cidade. Segundo a filosofia de Demócrito, a cidade somente conseguirá curar-se quando os homens passarem a empregar bem a razão.

Depois desse percurso, tornemos ao agora. Afinal, o que está doente, nós ou a cidade? Temos excesso de informação, de trânsito, de ruído... Talvez essa seja a hora de recordar a eudamonía de Demócrito e a ataraxía. Temos de ter o discernimento para saber daquilo que somos capazes e daquilo que não; e, através disso, buscar o equilíbrio para tornarmo-nos mais saudáveis, não só fisicamente, mas, ainda, através das relações que mantemos.

${ }^{40}$ Cf. Demócrito, DK 68 B 191 (tradução de Paulo F. Flor). 


\section{Referências}

ARISTÓTELES. O homem de gênio e a melancolia: o problema XXX, I. Trad. do grego, apresentação e notas de Jackie Pigeaud. Tradução para o português de A. Bueno. Rio de Janeiro: Lacerda, 1998.

AYACHE, L. Le cas de Démocrite: du diagnotic médical à l'évalutation philosophique. In: Wittem, R.; Pellegni, P. (org.). Hippokratische Medizin und antike Philosophie. Verhandlungen des VIII Internationalen Hippokrates-kolloquiums in Kloster Banz Staffelstein. Olms: Weidmann, 1993. Vol. XXIII, p. 63-75.

BURTON, R. Anatomie de la mélancolie. Traduction de B. Hoepffner, préface de J. Sarobinski. Paris: José Corti, 2000.

CAIRUS, H. F. A peste na literatura grega (acesso em 20 de maio de 2007, disponível no endereço: http://www.ufrgs.br/ANPUHRS/textos/A\%20Peste.pdf).

A fala razoável da loucura: o riso de Demócrito. Calíope. Rio de Janeiro, vol.11, p. 74- 81, 2003.

DARBO-PESCHANSKI, C. Ordre du corps, ordre du monde: aitia, tekmêrion, sêmeion, historion dans quelques traités hippocratiques de la fin du Ve. siècle avant notre ère. In: I Simpósio Internacional de Estudos Antigos-IV Seminário Internacional Archai: Saúde do homem e da cidade na Antiguidade Greco-Romana, 2007, Parque Natural do Caraça. Anais do I Simpósio Internacional de Estudos Antigos-IV Seminário Internacional Archai: Saúde do homem e da cidade na Antiguidade Greco-Romana. Belo Horizonte: FAFICH/ UFMG, 2007. Vol. I (cd-rom, p.1-9).

FINLEY, M. I. Política no mundo antigo. Tradução de Álvaro Cabral. Rio de Janeiro: Zahar, 1985.

. Democracia: antiga e moderna. Tradução de Waldéa Barcellos e Sandra Bedran. Rio de Janeiro: Graal, 1988.

de la FONTAINE, J. Démocrite et les Abdéritains (acesso em 30 de maio de 2007, disponível no endereço: <http://agora. qc.ca /thematiques /inaptitude.nsf/ Documents/Folie--Democrite_et_les_Abderitains _ pa JJean_de_La_Fontaine >). 
HIPÓCRATES. Da Natureza do Homem. In: CAIRUS, H. F; RIBEIRO Jr., W. A. Textos hipocráticos. O doente, o médico e a doença. Rio de Janeiro: FIOCRUZ, 2005, p. 39-59.

Ares, águas e lugares. In: CAIRUS, H. F.; RIBEIRO Jr., W. A. Textos hipocráticos. O doente, o médico e a doença. Rio de Janeiro: FIOCRUZ, 2005, p. 91129.

JONES, W. H. S. Philosophy and medicine in Ancient Greece. Baltimore: The Johns Hopkins Press: 1946, p 38-100.

MARSHAL, F. Súplica e responsabilidade. In: Édipo tirano. A tragédia do saber. Porto Alegre/ Brasília: UFRS/ UNB, 2000.

MOSSÉ, C. Dicionário da civilização grega. Tradução de Carlos Ramalhete e André Telles. Rio de Janeiro: Zahar, 2004.

MOULINIER, L. Le pur et l'impur dans la pensée des grecs. D'Homere a Aristote. Paris: Klincksieck, 1952.

PEIXOTO, M. C. D. A felicidade como simetria da alma em Demócrito. Boletim do C.P.A. Campinas, vol. 20/ 21, p. 117-131, 2007.

PIGEAUD, J. La maladie de l'âme. Étude sur la relation de l'âme et du corps dans la tradition médico-philosophique antique. Paris: Les Belles Lettres, 2006, p. 452-477.

PSEUDO-HIPPOCRATE. Sur le rire et la folie. Préface, traduction et notes d'Yves Hersant. Paris: Rivages poche, 1991.

SKINNER, Q. La philosophie et le rire. Conférences Marc Bloch (acesso em 22 de maio de 2007, disponível no endereço: < http://cmb.ehess.fr/document54.html>).

SOUZA, J. C. et alii. Os Pré-socráticos. Fragmentos, doxografia e comentários. Seleção de textos e supervisão de José Cavalcante de Souza, dados biográficos de Remberto Francisco Kuhnen, traduções de José Cavalcante de Souza et alii. São Paulo: Nova Cultural, 2000. 


\section{nuntius antiquus}

VERNANT, J.-P. As origens do pensamento grego. Tradução de Ísis Borges da Fonseca. São Paulo: Difel, 1986.

Sob os olhos do outro. In:

. Entre mito e política. Tradução de

Cristina Murachco. São Paulo: EDUSP, 2001, p. 343-345. 